\title{
Preparation of the Catalyst Support from the Oil-Shale Processing By- Product
}

\author{
F. Pérez-Caballero ${ }^{\mathrm{a}}$, A-L Peikolainen ${ }^{*}, \mathrm{a}$, M. Koel ${ }^{\mathrm{a}}$, M. Herbert ${ }^{\mathrm{b}}$, A. Galindo ${ }^{\mathrm{b}}$ and F. Montilla ${ }^{\mathrm{b}}$ \\ ${ }^{a}$ Institute of Chemistry, Tallinn University of Technology. Akadeemia tee 15, 12618 Tallinn, Estonia \\ ${ }^{b}$ Departamento de Quimica Inorginica, Universidad de Sevilla, Aptdo. 1203, 41071 Sevilla, Spain
}

\begin{abstract}
: 5-methylresorcinol and the technical mixture of oil-shale phenolic compounds were applied for carbon aerogel preparation. Gels, which were prepared via base catalyzed polymerization were dried under supercritical conditions and subsequent pyrolysis of obtained dry aerogels led to carbon aerogels. Activation of carbon aerogel with $\mathrm{CO}_{2}$ and $\mathrm{H}_{2} \mathrm{O}$ was performed and porosity and the specific surface area of activated carbon aerogels were studied. Langmuir specific surface areas of well over $2000 \mathrm{~m}^{2} / \mathrm{g}$ were achieved and microporosity of carbon aerogel samples was tuneable ranging from below $50 \%$ until over $85 \%$. Impregnation with the complex $\left[\mathrm{Pd}\left(\mathrm{C}_{4} \mathrm{HF}_{6} \mathrm{O}\right)_{2}\right]$ was carried out in supercritical $\mathrm{CO}_{2}$ using $\mathrm{H}_{2}$ for a quick reduction of $\mathrm{Pd}(\mathrm{II})$ to $\mathrm{Pd}(0)$. Eventually, highly porous material decorated with nanoparticles of black palladium was obtained having a homogeneous metal distribution.
\end{abstract}

\section{INTRODUCTION}

In Estonia, oil-shale is the most important local solid fossil fuel, being a major source of energy. By fuel and crude oil production a remarkable amount of by-products is generated. Oil-shale processing by-products such as phenolic mixtures have been used as raw material in the chemical industry only moderately (less than 8\%) [1]. Alkylresorcinols have been used in pharmaceuticals, food additives, cosmetics, biocides, fungicides, dyes, high value photoactive resins and novolacs in the electronics industry, as additives in the plastic industry as well as UV protectors, antioxidants, and stabilizers in the rubber industry [2]. This article will discuss yet another application of alkylresorcinols, i.e. the application of purified 5-methylresorcinol as a precursor to carbon aerogel preparation. Furthermore, the technical mixture of phenols generated in the oil-shale industry, Honeyol ${ }^{\mathrm{TM}}$, may be employed in carbon aerogel preparation without prior purification. The possible use of the carbon aerogel impregnated with black palladium is proposed for catalytic purposes.

Carbon aerogel is a highly porous carbon material with low density and large specific surface area. These properties allow the usage of the gel as adsorbent, membrane and carrier of metal catalysts. Furthermore, carbon aerogels may be used as electrode materials because of their controllable porous structure and electrically conductive network [3].

The preparation of carbon aerogel starts with that of organic gel. The gel obtained is then dried under supercritical conditions. The dried gel is pyrolysed in an inert atmosphere at high temperature and carbon aerogel will be obtained. The coexistence of micropores and mesopores can extend their potential for applications $[4,5]$. Activation has been proven to be very effective to improve the porosity of carbon aerogels and increase their specific surface area. The activation

*Address correspondence to this author at the Institute of Chemistry, Tallinn University of Technology. Akadeemia tee 15, 12618 Tallinn, Estonia; Tel: +372 620 4325; Fax: +372 620 2828; E-mail: annnaliiisa@gmail.com time is crucial to selecting the final pore size and specific surface area. Studies on activation using $\mathrm{H}_{2} \mathrm{O}$ instead of $\mathrm{CO}_{2}$ have been reported [6].

The use of carbon as a catalyst carrier is widely recognized $[7,8]$. To impregnate the carbon network with metal nanoparticles, several methods have been developed, most starting with the impregnation of an oxidized salt or metal complex followed by the reduction [9-11]. A number of methods for reduction of the metal have been employed including thermal decomposition in an inert atmosphere and chemical conversion with hydrogen or air. The relatively new method is the chemical reduction in the supercritical fluid with a reducing agent such as hydrogen or an alcohol or thermal reduction in the supercritical fluid [12].

Pekala was the first to prepare aerogels from organic materials in the $1980 \mathrm{~s}$, using resorcinol as a phenolic precursor [13]. In the latter capacity, phenol $[14,15]$ and phloroglucinol [16] have also been used. The most thoroughly studied method of aerogel preparation developed by Pekala employs resorcinol $(\mathrm{R})$ and formaldehyde $(\mathrm{F})$ as precursors, sodium carbonate as catalyst (C) and water (W) as solvent [17]. The gel is prepared via a double-catalyzed base-acid synthesis, in the course of which it is first cured in basic conditions at 358 $\mathrm{K}$ for $36 \mathrm{~h}$ (preferably from $48 \mathrm{~h}$ to 7 days). The gel formed is then acid-washed at $318 \mathrm{~K}$ for 3 days to promote a further cross-linking of the gel. This will impart stability to the gel structure, and remove the excess base [13].

5-methylresorcinol, due to its molecular structure is an attractive precursor, unlike resorcinol, as faster gelling could be expected. Also, another important aspect adds value- 5methylresorcinol costs less.

\section{MATERIALS AND METHODOLOGY}

Anhydrous 5-methylresorcinol (MR) with a reported purity of $99.58 \%$ was obtained from Carboshale AS, Estonia, and was used as received. Anhydrous sodium carbonate with a purity of $99.8 \%$, Riedel-de-Haen, Germany was also used 
as received. The water used was purified using a Milli-Q Water system. Formaldehyde (a $37 \% \mathrm{w} / \mathrm{w}$ solution in water), Sigma-Aldrich, was used as received. Palladium (II) hexafluoroacetylacetonate $\left[\mathrm{Pd}\left(\mathrm{C}_{4} \mathrm{HF}_{6} \mathrm{O}\right)_{2}\right]$ was obtained from Aldrich and was used as received.

Honeyol $^{\mathrm{TM}}(\mathrm{H})$, which is a product of Viru Keemia Grupp, Estonia, was obtained from the Institute of Oil-Shale at Tallinn University of Technology; potassium hydroxide was from Chemapol Lachema Brno, Czech Republic; formaldehyde was in the form of a $35 \% \mathrm{w} / \mathrm{w}$ solution in methanol. The solution was made by dissolving paraform in methanol. Paraform (purity 95\%) was from Sigma Aldrich Laborchemikalien $\mathrm{GmbH}$, Germany; methanol used was an HPLC reagent, Rathburn Chemicals Ltd., Scotland.

The thermostat for gelation: a TECHNE Dri-Block ${ }^{\circledR}$ DB $3 \mathrm{~A}$, Spain; supercritical drying was performed on a modular extraction system (the extractor volume $100 \mathrm{~mL}$ ) constructed by an NWA Analytische Mesgerate GmbH, Germany. Carbon dioxide with purity $99.8 \%$ was from Eesti AGA.

The gels based on 5-methylresorcinol were prepared using Pekala's procedure: 5-methylresorcinol and $\mathrm{Na}_{2} \mathrm{CO}_{3}$ were dissolved in water and the formaldehyde solution was added. The gel was formed at $298 \mathrm{~K}$ and after $24 \mathrm{~h}$ of curing, the gel piece was transferred into acetone prior to drying, replacing acetone every $24 \mathrm{~h}$ with the fresh one. The exchange of the solvent was carried out at least 4 times; every time the volume of acetone was ten times the volume of the gel piece. The gel was dried using supercritical $\mathrm{CO}_{2}$.

The Honeyol ${ }^{\mathrm{TM}}$-formaldehyde gels were prepared by dissolving Honeyol ${ }^{\mathrm{TM}}$ in methanol, adding a $6 \% \mathrm{KOH}$ solution in methanol and a $35 \%$ formaldehyde solution in methanol. Gelation was carried out at $333 \mathrm{~K}$. Then the gel was dried using supercritical $\mathrm{CO}_{2}$.

The pyrolysis was studied using MR-F aerogels. The carbon aerogels obtained were further used for impregnating with catalyst. The pyrolysis of the dried aerogel was performed in an inert atmosphere $\left(\mathrm{N}_{2}\right)$ in a tubular furnace, with a working temperature of up to $1053 \mathrm{~K}$, and controlled by a Nabertherm Program Controller S19 (Germany). The furnace was cooled to room temperature under its own thermal mass after the pyrolysis was completed.

Activation was carried out after pyrolysis by leaving the gel in the tubular furnace and raising the temperature up to $1173 \mathrm{~K}$ in the flow of $\mathrm{CO}_{2} . \mathrm{H}_{2} \mathrm{O}$ was also used as activating agent.

The composition and morphology of organic and carbon aerogels were analysed by an EDAX JEOL 6042 analyser and a Leo Supra 35 Scanning Electron Microscope (SEM). For nitrogen adsorption analyses, a Sorptometer KELVIN 1042 built by Costech International was used: the gas volume $\left(\mathrm{N}_{2}\right)$ adsorbed on the surface of materials at liquid nitrogen temperature was measured. The precision of the measurements data of the adsorbed gas volume was $\leq 3 \%$. Helium was used as a carrier gas with nitrogen as an adsorptive gas. The Langmuir specific surface area was calculated according to the Brunauer-Emmet-Teller (BET) theory. The specific micropore volume $\left(\mathrm{V}_{\text {mic }}\right)$ was determined via the $\mathrm{t}$ plot and the pore size distributions were determined using the Barrett-Johner-Halendar (BJH) theory. To calculate the specific surface areas, $\mathrm{P} / \mathrm{P}_{\mathrm{o}}$ was in the range of $0.05-0.25$; to determine the micropore volumes, $\mathrm{P} / \mathrm{P}_{\mathrm{o}}$ was from 0.0005 0.4 .

\section{RESULTS AND DISCUSSION}

\section{Aerogel preparation}

Similarly to resorcinol, 5-methylresorcinol is a trifunctional molecule with reaction sites at the $2^{\text {nd }}, 4^{\text {th }}$ and $6^{\text {th }}$ positions of the aromatic ring where the addition of a bifunctional formaldehyde results in the formation of hydroxymethyl $\left(-\mathrm{CH}_{2} \mathrm{OH}\right)$ groups. In case of 5-methylresorcinol the gel formation was faster and the temperature lower because of the presence of an additional directing group ($\left.\mathrm{CH}_{3}\right)$ in the $5^{\text {th }}$ position of the aromatic ring unlike resorcinol. The gel was formed at $298 \mathrm{~K}$ within 100 minutes and was ready for handling after $24 \mathrm{~h}$. The gel was directly transferred into acetone, excluding the step of aging in acidic media. The infrared spectrometric analysis showed no advantage of double-catalyzed synthesis over single-step basecatalyzed synthesis in bond formation. Neither the radial shrinkage during drying nor the density decreased due to curing in acidic media.

During the drying, the volume of the aerogel decreases compared to the gel that contains the solvent, especially if ambient pressure and temperature are applied while drying. During the conventional drying, the receding meniscus in the interface of the liquid and the gaseous phase lead to capillary pressure which shrinks the pores or even leads to the cracking of the fragile solid skeleton of the gel. To avoid the formation of the meniscus and generation of capillary pressures while drying, in the reactor supercritical state of the fluid must be used. At its supercritical state water is extremely reactive and the decomposition of polymer may occur. Because of its low critical parameters $\left(\mathrm{T}_{\mathrm{c}}=304.25 \mathrm{~K} ; \mathrm{P}_{\mathrm{c}}=7.38\right.$ $\mathrm{MPa}$ ) carbon dioxide is the most suitable fluid to be used for supercritical drying. Carbon dioxide is also non-flammable, non-toxic, environmentally friendly and inexpensive and leaves no residues in the treated medium [18]. Also, the polarity of $\mathrm{CO}_{2}$ is suitable for removing most of the organic solvents used for the sol-gel preparation of organic polymers [19]. In order to use supercritical $\mathrm{CO}_{2}$ drying, water in the gel pores is replaced with another solvent miscible with $\mathrm{CO}_{2}$. In this work acetone was used.

Attempts to prepare the Honeyol ${ }^{\mathrm{TM}}$-formaldehyde gel $(\mathrm{H}-$ F) in a similar way as MR-F gel showed that in case of the former a stronger basic catalyst for cross-linking and also higher temperatures for gelling are needed. The formation of the H-F gel is hindered because Honeyol ${ }^{\mathrm{TM}}$ contains apart from $59.6 \%$ of 5 -methylresorcinol dihydroxy benzenes with additional substitutions at the positions where the directing groups would affect formaldehyde to react. The gel remained intact when methanol, which is also miscible with $\mathrm{CO}_{2}$, was used for the solvent replacement instead of acetone. Further on methanol was used as a solvent throughout the process similar to [20].

The aerogel is composed of interconnected nanometre sized particles. The pore and particle size of the material can easily be tailored by varying the concentrations of components (reagents, catalyst and solvent). The most efficient method for modifying pore characteristics is changing the 
amount of the catalyst in the sol: the higher amount of the catalyst affects the density, specific surface area and mechanical properties of dried aerogels. The shrinkage is the most considerable in case of gels prepared using a high loading of catalyst [21].

The optimization of concentrations of H-F and MR-F organic aerogels was carried out with the aim to achieving the lowest density and minimal radial shrinkage after drying [22-24]. In the experiments carried out by the authors an optimal duration of supercritical $\mathrm{CO}_{2}$ drying was less than $4.5 \mathrm{~h}$, as after a longer processing no further decrease in aerogel density or radial shrinkage was observed. The specific surface area was also measured. At optimal molar ratios, the drying shorter than $4.5 \mathrm{~h}$ resulted in the MR-F aerogel with a radial shrinkage of $2 \%$, density of $0.21 \mathrm{~g} / \mathrm{cm}^{3}$ and specific surface area of $350 \mathrm{~m}^{2} / \mathrm{g}$.

In both cases the optimal concentrations of reagents were the following: $\mathrm{MR} / \mathrm{F}=\mathrm{H} / \mathrm{F}=0.5, \mathrm{MR} / \mathrm{C}=\mathrm{H} / \mathrm{C}=60$ and water $/ \mathrm{MR}=$ methanol $/ \mathrm{H}=60$ (C- moles of catalyst). At the same molar ratios of the H-F the shrinkage of the aerogel was $29 \%$, specific surface area $302 \mathrm{~m}^{2} / \mathrm{g}$ and the density 0.10 $\mathrm{g} / \mathrm{cm}^{3}$. From Honeyol ${ }^{\mathrm{TM}}$, it was possible to prepare an aerogel with a specific surface area of $469 \mathrm{~m}^{2} / \mathrm{g}$. The shrinkage of the H-F aerogel was $20-30 \%$ due to the water generated in the polycondensation reaction. In case of Honeyol ${ }^{\mathrm{TM}}$ the double-step base-acid catalysis could not be favoured because it is known that in the presence of an acid catalyst, the unreacted formaldehyde present in methanol leads to the formation of hemiformal [25], hindering a further crosslinking between the molecules, which results in more considerable shrinkage. Infrared spectra also showed no advantage of double-catalyzed synthesized gels over the singlestep catalyzed ones in terms of gel formation.

\section{Carbon Aerogel Preparation}

The microporosity of carbon aerogels can be tailored by modifying the pyrolysis conditions. Through the $\mathrm{N}_{2}$ adsorption isotherm, information on the accessible surface area and overall porosity is generally obtained. The porosity that is not accessible for $\mathrm{N}_{2}$ at $77 \mathrm{~K}$ can be considered a surface area reservoir that can be made accessible via activation. The carbon burn-off is an indicator of the micropore volume and surface area obtained during activation. Via the
$\mathrm{CO}_{2}$-activation of carbon aerogels the surface area can be increased from 500 to well over $2000 \mathrm{~m}^{2} / \mathrm{g}$ with the carbon burn-off of only $50 \%$. It has been reported that the increase in the micropore volume more than $1 \mathrm{~cm}^{3} / \mathrm{g}$ observed during the $\mathrm{N}_{2}$-adsorption is due to an opening of initially inaccessible micropores and the creation of new voids [26]. A highly accessible surface area of the material is needed for applications in supercapacitors and fuel cells. Indeed, a large micropore volume is a prerequisite.

The pyrolysis was performed by placing the gels in a tubular furnace in the flow of nitrogen following the program described in Fig. (1). The final temperature of pyrolysis was $1053 \mathrm{~K}$. This was shown to be optimum after having observed that the mass loss of the aerogel above this temperature is very low and the change in the porosity as well as specific surface area is negligible.

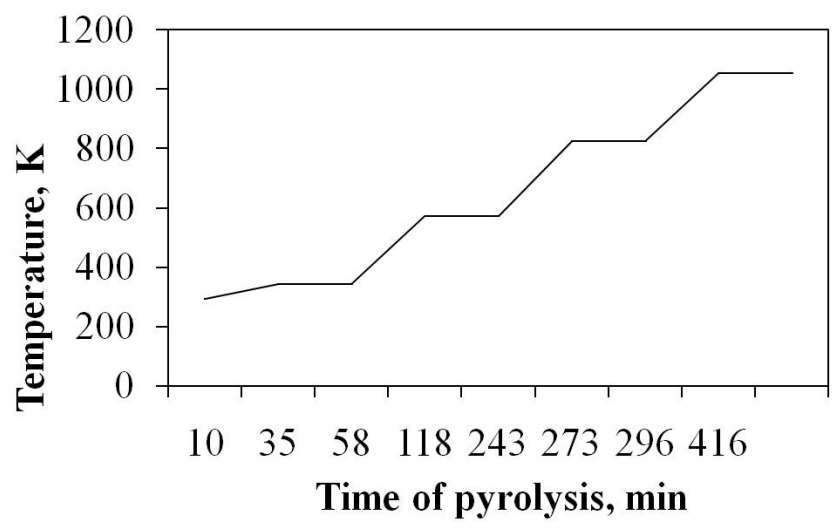

Fig. (1). The temprature program of pyrolysis.

\section{Activation of Carbon Aerogel}

Activation differs from pyrolysis in the temperature program and in the carrier gas. The effect of activation time on the porosity of the carbon aerogel was studied using $\mathrm{H}_{2} \mathrm{O}$ or $\mathrm{CO}_{2}$ as carriers in the reactor which was heated from room temperature up to $1173 \mathrm{~K}$ at a rate of 10 degrees per minute. After the final activation temperature was reached, the gel was left at this temperature for the time described in Table $\mathbf{1}$ as activation time. The table also presents the results of ni-

Table 1. Characteristics of the Samples Under Study

\begin{tabular}{|c|c|c|c|c|c|c|c|c|}
\hline Sample & Activation Time, $\mathrm{h}$ & $\mathbf{V}_{\text {mic }}, \mathrm{mm}^{3} / \mathrm{g}$ & $\mathbf{V}_{\text {total }}, \mathbf{m m}^{3} / \mathrm{g}$ & $\mathbf{S}_{\text {mic }}, \mathbf{m}^{2} / \mathbf{g}$ & Langmuir Surface, $\mathrm{m}^{2} / \mathrm{g}$ & $\%_{\text {mic }}$ & Density, $\mathbf{g} / \mathrm{cm}^{3}$ & Mass Loss, $\%$ \\
\hline Aerogel & - & 0 & $\mathrm{NA}^{+}$ & 0 & 404.92 & 0 & 0.206 & - \\
\hline $\mathrm{ACA}-\mathrm{CO}_{2} 1$ & 0.5 & 263.2 & 812.9 & 747.00 & 1429.17 & 72.60 & 0.245 & 27.33 \\
\hline $\mathrm{ACA}-\mathrm{CO}_{2} 2$ & 1 & 290.7 & $\mathrm{NA}^{+}$ & 825.10 & NA & 85.10 & 0.217 & 33.40 \\
\hline $\mathrm{ACA}-\mathrm{CO}_{2} 4$ & 2 & 261.2 & 1253.3 & 741.20 & 2289.99 & 44.80 & 0.158 & 66.92 \\
\hline ACA- $\mathrm{H}_{2} \mathrm{O} 1$ & 0.5 & 137.0 & 903.1 & 388.79 & 965.44 & 54.54 & 0.307 & 24.46 \\
\hline ACA- $\mathrm{H}_{2} \mathrm{O} 2$ & 2 & 198.5 & $\mathrm{NA}^{+}$ & 563.22 & 1018.96 & 73.09 & 0.311 & 25.09 \\
\hline ACA- $\mathrm{H}_{2} \mathrm{O} 3$ & 4 & 149.4 & 876.3 & 423.97 & 927.06 & 62.17 & 0.287 & 42.99 \\
\hline
\end{tabular}

${ }^{+} \mathrm{NA}$ - not available. 
trogen adsorption measurements applied to the activated carbon aerogels. CA in Table 1 marks carbon aerogel, ACA is activated carbon aerogel. $\mathrm{V}_{\text {mic }}$ is the volume occupied by micropores. $\mathrm{V}_{\text {total }}$ and $\mathrm{S}_{\text {mic }}$ are total pore volume and microporous area of activated carbon aerogels. $\%_{\text {mic }}$ is the percentage of microporosity in the samples. ACA- $-\mathrm{CO}_{2}$ and ACA- $\mathrm{H}_{2} \mathrm{O}$ refer to the samples activated using carbon dioxide and water, respectively, as activating agents.

It may be seen that the increase of the time of activation of the samples leads to an increase in the total pore volume of the latter, reaching over $1200 \mathrm{~mm}^{3} / \mathrm{g}$ after $2 \mathrm{~h}$ of activation. Equally, there is an increase in the Langmuir specific surface area from $600 \mathrm{~m}^{2} / \mathrm{g}$ in case of non-activated samples to well over $2000 \mathrm{~m}^{2} / \mathrm{g}$ in case of samples activated for over $1 \mathrm{~h}$ under the $\mathrm{CO}_{2}$ flow, almost reaching the specific surface area of R-F carbon aerogels [4]; the specific surface area of over $1000 \mathrm{~m}^{2} / \mathrm{g}$ was achieved for samples activated under the $\mathrm{H}_{2} \mathrm{O}$ flow as seen in Fig. (2).

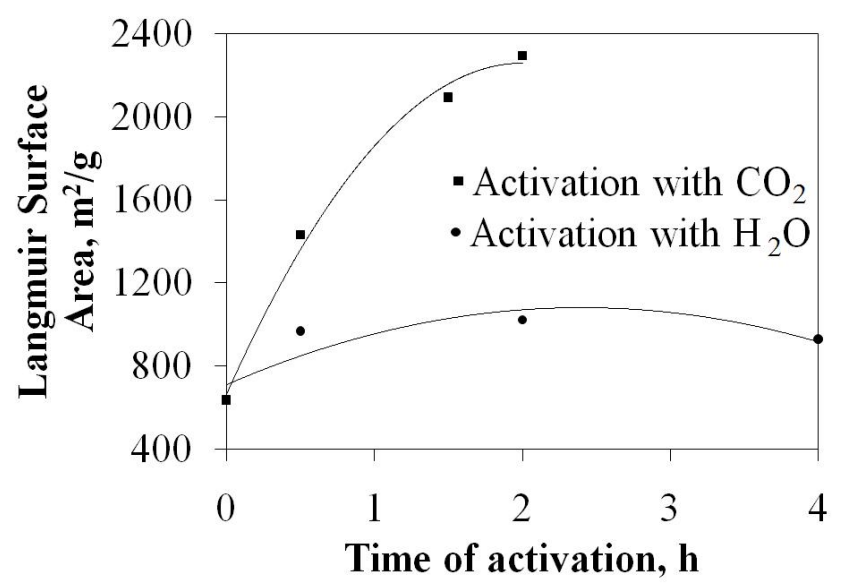

Fig. (2). The Langmuir surface area of the samples under study activated with both water and carbon dioxide.

Judging by the values obtained much higher specific surface area in case of the activation time of over $2 \mathrm{~h}$ for $\mathrm{CO}_{2}$ seem unlikely as the mass loss is already over $65 \%$ at this time of activation.

In Fig. (3), it may be seen that activation plays a fundamental role in the final appearance of carbon aerogels.

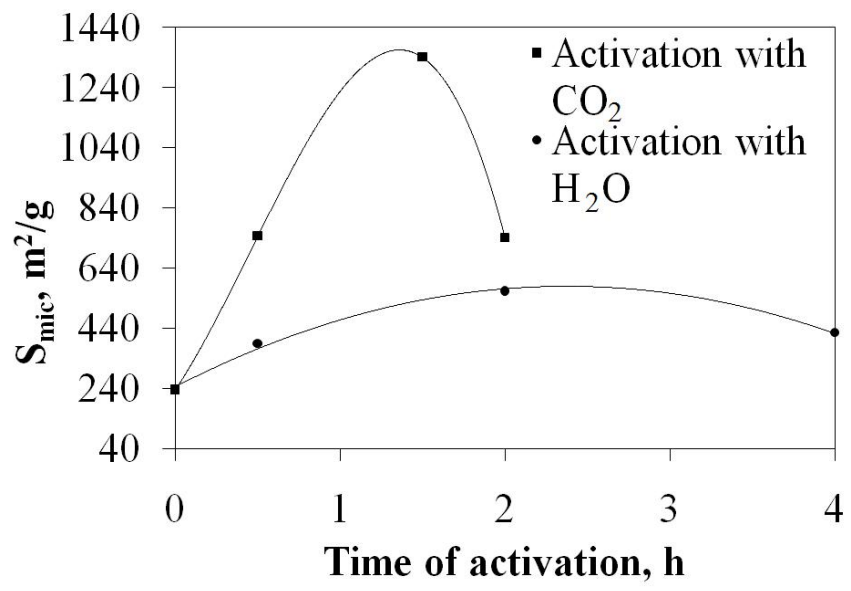

Fig. (3). Microporous area versus time of activation.
During the activation between 60 and 90 minutes, the microporosity of gels reached maximum and samples with a microporosity of over $1400 \mathrm{~m}^{2} / \mathrm{g}(90 \%$ of total area) were formed. However, when the activation time was increased further, samples with a microporosity below $800 \mathrm{~m}^{2} / \mathrm{g}$ (less than $50 \%$ of microporosity) were formed. The same effect was observed in case of samples activated for 30 minutes or less.

The density of the carbon aerogels activated under $\mathrm{CO}_{2}$ for $2 \mathrm{~h}$ was below $0.16 \mathrm{~g} / \mathrm{cm}^{3}$. The mass loss of the gels was almost $70 \%$. Considering this tendency it is expected that in these conditions activation cannot be carried out for a much longer time than $2 \mathrm{~h}$. In case of activation using $\mathrm{H}_{2} \mathrm{O}$, there is a mass loss which remains constant during the first few hours of activation. After $4 \mathrm{~h}$, the mass loss is over $40 \%$ but the maximum specific surface area seems to have appeared within the first $3 \mathrm{~h}$ as shown in Fig. (2).

\section{Impregnation of Carbon Aerogel}

In order to impregnate carbon aerogels with palladium nanoparticles, a quantity of a carbon aerogel was weighed and placed in a high-pressure reactor. Subsequently, $\operatorname{Pd}\left(\mathrm{C}_{4} \mathrm{HF}_{6} \mathrm{O}\right)_{2}$ was added together with a stirring bar. The reactor was then sealed and placed in a bath at $313 \mathrm{~K}$. The amount of the Pd complex weighed was in the range of 1015 mass percent of the carbon aerogel mass. $\mathrm{CO}_{2}$ was then pumped in up to a pressure of $15 \mathrm{MPa}$ and the system was left for $2 \mathrm{~h}$ in order to allow the palladium complex time to dissolve. Then, a mixture $\mathrm{CO}_{2}: \mathrm{H}_{2}(15: 1)$ was pumped in until the final pressure in the reactor was $18.5 \mathrm{MPa}$. Then, the system was left to react for 25 minutes before slow decompression. After opening the reactor, the carbon decorated with palladium nanoparticles was obtained and analysed. Fig. (4) shows how the carbon network of the aerogel was decorated with palladium nanoparticles after the reduction and decompression in the reactor.

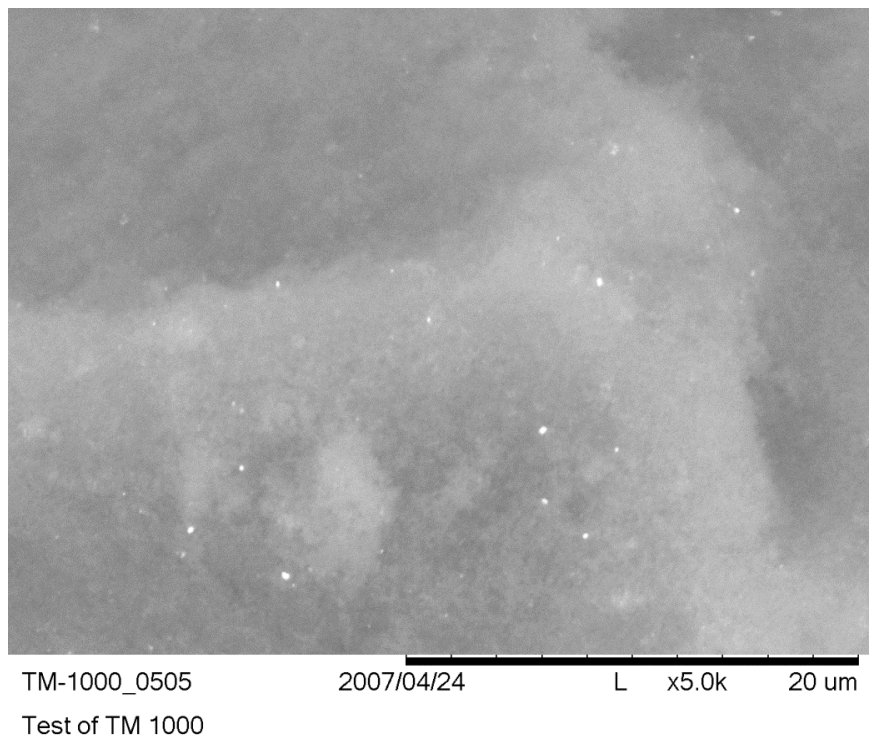

Fig. (4). A SEM image of the piece of carbon aerogel impregnated with black palladium.

The catalyst was tested in the reduction of ciscyclooctene into cyclooctane in supercritical $\mathrm{CO}_{2}$ having basically a total conversion in the quick reaction. Moreover, 
the impregnated piece of carbon aerogel was reused several times in the same reaction reaching the same level of conversion.

\section{CONCLUSIONS}

For aerogel preparation, 5-methylresorcinol and its technical mixture, Honeyol ${ }^{\mathrm{TM}}$, were shown to be very competitive precursors beside the well-studied resorcinol. An easy control of the gel structure by varying the concentrations of reagents, led to materials with low density and high specific surface area. The preparation of MR-F and H-F aerogels was effective via a single-step base-catalyzed synthesis. Supercritical conditions were necessary for drying the wet gel in order to maintain the high porosity of aerogels.

The final properties of gels could also be tailored during pyrolysis and activation as was shown in this study. Samples with high microporosity and large specific surface area as well as samples with a higher value of the specific surface area characterized by being constituted by mesopores mainly were produced. The activation time of over $2 \mathrm{~h}$ led to too high mass loss and consequently, a total burn-off of samples when the activating agent was $\mathrm{CO}_{2}$. In case of using $\mathrm{H}_{2} \mathrm{O}$ the mass loss was below $50 \%$ during $4 \mathrm{~h}$.

Using a $\mathrm{CO}_{2}$-soluble palladium salt, the impregnation of carbon aerogels was successfully carried out. The rapid reaction led to samples which were homogeneously decorated with black palladium.

\section{ACKNOWLEDGEMENTS}

This work was supported by the European Commission under the Marie Curie RTN "SuperGreenChem" EC Contract No. MRTN-2003-504005 and the Estonian Science Foundation (Grant No 7303).

Mai Uibu and Rein Kuusik are acknowledged for performing analyses using nitrogen adsorption and Olga Volobujeva for performing analyses using SEM.

\section{REFERENCES}

[1] M. Koel, and J. Bunger, "Overview of Program on US- Estonian Science and Technology Cooperation on Oil Shale Research and Utilization," Oil Shale, vol. 22, pp. 65-79, March 2005.

[2] A. Vagel, and E. Roo "Alkylresorcinols- rare chemicals available in bulk," Innov. Pharm. Tech., pp. 94-95, 2004.

[3] R. Saliger, U. Fischer, C. Herta, and J. Fricke, "High surface area carbon aerogels for supercapacitors," J. Non-Cryst. Solids, vol. 225, pp. 81-85, April 1998.

[4] Y. Hanzawa, K. Kaneko, R. W. Pekala, and M. S. Dresselhaus, "Activated carbon aerogels," Langmuir, vol. 12, pp. 6167-6169, 2006.

[5] C. Ishii, Y. Matsumura, and K. Kaneko, "Ferromagnetic behavior of superhigh surface area carbon," J Phys Chem US, vol. 99, pp. 5743-5745, 1995.
[6] A. Jänes, H. Kurig, and E. Lust, "Characterisation of activated nanoporous carbon for supercapacitor electrode material," Carbon, vol. 45, pp. 1226-1233, May 2007.

[7] G. M. Pajonk, "Catalytic aerogels," Catal Today, vol. 35, pp. 319337, March 1997.

[8] R. Y. Xiang, L. Yuehe, and M. W. Chien, "Decorating catalytic palladium nanoparticles on carbon nanotubes in supercritical carbon dioxide", Chem. Commun., pp. 642-643, 2003.

[9] C. D. Saquing, D. Kang, M. Aindow, and C. Erkey, "Investigation of the supercritical deposition of platinum nanoparticles into carbon aerogels," Micropor. Mesopor. Mater., vol. 80, pp. 11-23, May 2005.

[10] L. C. Cotet, M. Gich, A. Roig et al. "Synthesis and structural characteristics of carbon aerogels with a high content of $\mathrm{Fe}, \mathrm{Co}, \mathrm{Ni}, \mathrm{Cu}$, and Pd," J. Non-Cryst. Solids, vol. 352, pp. 2772-2777, August 2006.

[11] S. Cacchi, C. L. Cotet, G. Fabrizi, et al. "Efficient hydroxycarbonylation of aryl iodides using recoverable and reusable carbon aerogels doped with palladium nanoparticles as catalyst," Tetrahedron, vol. 63, pp. 2519-2523, March 2007.

[12] Y. Zhang, and C. Erkey, "Preparation of supported metallic nanoparticles using supercritical fluids: A review," J Super Crit Fluids, vol. 38, pp. 252-267, September 2006.

[13] R. W. Pekala, "Low density, resorcinol-formaldehyde aerogels," US Patent 4,873,218, October 10, 1989.

[14] D. Wu, R. Fu, Z. Sun, and Z. Yu, "Low-density organic and carbon aerogels from the sol-gel polymerization of phenol with formaldehyde," J. Non-Cryst. Solids, vol. 351, pp. 915-921, April 2005.

[15] M. F. Grenier-Loustalot, S. Larroque, D. Grande, P. Grenier, and D. Bedel, "Phenolic resins: 2. Influence of catalyst type on reaction mechanisms and cinetics," Polymer, vol. 37, pp. 1363-1369, April 1996.

[16] K. Barral, "Low-density organic aerogels by double-catalysed synthesis," J. Non-Cryst. Solids, vol 225, pp. 46-50, April 1998.

[17] R. W. Pekala, "Low density, resorcinol-formaldehyde aerogels," US Patent 4,997,804, March 1991.

[18] C. D. Wood, B. Tan, H. Zhang, and A. I. Cooper, "Supercritical carbon dioxide as a green solvent for polymer synthesis," Thermodynamics, Solubility and Environmental Issues, pp. 383-396, 2007.

[19] M. Perrut, and E. Francais, "Process and equipment for drying a polymeric aerogel in the presence of a supercritical fluid," US Patent 5,962,539, October 5, 1999.

[20] G. Qin, and S. Guo, "Preparation of RF organic aerogels and carbon aerogels by alcoholic sol-gel process," Carbon, vol. 39, pp. 1929-1941, October 2001.

[21] R. W. Pekala, and D. W. Schaefer, "Structure of Organic Aerogels. 1. Morphology and Scaling," Macromolecules, vol. 26, pp. 54875493, 1993.

[22] F. Pérez-Caballero, A.-L. Peikolainen, M. Uibu, R. Kuusik, O. Volobujeva, and M. Koel, "Preparation of carbon aerogels from 5methylresorciol-formaldehyde gels," Micropor Mesopor Mater, vol. 108, pp. 230-236, February 2008.

[23] F. Pérez-Caballero, A.-L. Peikolainen, and M. Koel, "Preparation of nanostructured carbon materials," Proceedings of the Estonian Academy of Sciences: Chemistry, vol. 57, pp. 48-53, March 2008.

[24] A.-L. Peikolainen, F. Pérez-Caballero, and M. Koel, "Low-density organic aerogels from oil shale by-product 5-methylresorcinol," Oil Shale, submitted, Registration No: 31/07.

[25] McMurry, Organic chemistry: International Student Edition. 6th ed. London: Brooks/Cole, 2004.

[26] R. Saliger, G. Reichenauer, and J. Fricke "Evolution of microporosity upon $\mathrm{CO}_{2}$-activation of carbon aerogels," Studies in Surface Science and Catalysis, vol. 128, pp. 381-390, 2000. 